\title{
Urban-rural differences in incidence rates of psychiatric disorders in Denmark
}

\author{
Evangelos Vassos, Esben Agerbo, Ole Mors and Carsten Bøcker Pedersen
}

\section{Background}

People born in densely populated areas have a higher risk of developing schizophrenia, bipolar disorder and autism.

\section{Aims \\ The purpose of this study was to investigate whether urban- rural differences in place of birth influence a broad range of mental disorders. \\ Method \\ Population-based cohort study of everyone born in Denmark between 1955 and $2006(n=2894640)$. Main outcome measures were incidence rate ratios for five levels of urbanisation and summary estimates contrasting birth in the capital with birth in rural areas. \\ Results \\ For all psychiatric disorders, except intellectual disability (ICD-10 'mental retardation') and behavioural and emotional}

disorders with onset in childhood, people born in the capital had a higher incidence than people born in rural areas.

\section{Conclusions}

Birth in an urban environment is associated with an increased risk for mental illness in general and for a broad range of specific psychiatric disorders. Given this new evidence that urban-rural differences in incidence are not confined to the well-studied psychotic disorders, further work is needed to identify the underlying aetiopathogenic mechanisms.

\section{Declaration of interest}

None.

\section{Copyright and usage}

(c) The Royal College of Psychiatrists 2016.
Regional variation in mental health may result from preventable environmental causes and inform public health interventions. Many studies have been conducted comparing the rates of psychiatric disorders between urban, and rural environments, with inconsistent findings. Evidence for the more prevalent mood, anxiety and substance use disorders, reviewed by Peen et al, indicates increased rates in residents of urban in comparison with rural environments and a link between higher social problems and environmental stressors in cities and increased psychiatric morbidity has been hypothesised. The evidence for the effect of urbanicity on other common mental health disorders, including personality disorders, eating disorders and attention-deficit hyperactivity disorder (ADHD), is limited and inconclusive. ${ }^{2,3}$ However, no causal inferences can be based on studies of prevalent cases examining urbanicity at the time of enrolment, because of methodological limitations; most importantly the increased mortality and emigration in people with a mental illness but also the hypothesised drift towards cities of individuals with mental illness. $^{4}$ The most systematically examined psychiatric disorder for the effect of urbanicity on incidence is schizophrenia, with consistent evidence that urban environment is associated with a higher risk for the disorder. ${ }^{5,6}$ Although not known, the underlying cause(s) responsible for these differences have been hypothesised to include toxic exposures, diet, infections, stress or an artefact because of selective migration or treatment-seeking behaviour. Although confounding may explain part of the effect, as for example high rates of schizophrenia in cities can be secondary to higher rates of substance misuse or ethnic minority status in comparison with rural places, studies accounting for a variety of confounders have confirmed the association. ${ }^{7}$ Only a few studies have considered urban-rural differences in the incidence of bipolar affective disorder, ${ }^{8-10}$ depression $^{10,11}$ and autism. ${ }^{12,13}$ It remains unknown whether urbanicity influences the incidence of other mental disorders. Examining the effect of urbanicity in a broad range of mental disorders would be useful in order to explore similarities and differences of categorical mental diagnoses as identified through the current classification systems and to direct further research aiming to identify the underlying causal effects of urbanicity (i.e. looking at aetiological factors that have been associated specifically with psychosis or with a broader risk for mental illness). Based on a large nationwide population, we aimed to investigate whether urban-rural differences at place of birth influence the full spectrum of mental disorders including, among others, substance misuse, schizophrenia, mood disorders, neurotic and stress-related disorders, eating disorders, intellectual disability (ICD-10 'mental retardation'), pervasive developmental disorders and hyperkinetic disorder.

\section{Method}

\section{Study population}

The Danish Civil Registration System (CRS) was established in 1968, where all people living in Denmark were registered. Among other variables, it includes information on personal identification number, gender, date and place of birth, continuously updated information on vital status and also the parent's personal identifiers. The personal identification number is used in all national registers enabling accurate linkage between registers. Our study population included all individuals born in Denmark between January 1955 and 31 December 2006 and with both parents also born in Denmark.

\section{Assessment of mental illness}

People within the study cohort and their parents and siblings were linked via their personal identifier to the Danish Psychiatric Central Research Register ${ }^{14}$ to obtain information about mental illness. This register was computerised in 1969 and contains data on all admissions to Danish psychiatric in-patient facilities and, from 1995, information on out-patient visits to psychiatric 
departments. From 1969 to 1993 the diagnostic system used was the Danish modification of ICD- $8^{15}$ and from 1994 the ICD-10. ${ }^{16}$ Cohort members were classified with a mental disorder if they had been admitted to a psychiatric hospital or had received out-patient care. The spectrum of mental disorders considered is shown in Table 1. We examined the main categories of ICD-10 and the most common and characteristic disorders within these categories. For each mental disorder, the date of onset was defined as the first day of the first contact (in-patient or out-patient) with the diagnosis of interest. Multiple disorders were recorded if developed by the individual. Parents and siblings were classified as having a history of mental disorder if they had been admitted to a psychiatric hospital or had been in out-patient treatment for any reason.

\section{Assessment of urbanisation at birth}

Municipalities in Denmark were classified according to degree of urbanisation ${ }^{17}$ as follows: capital, capital suburb, provincial cities, provincial towns or rural areas. Denmark is a small homogeneous country with a population of 5.3 million people and a total area of $43000 \mathrm{~km}^{2}$. The population densities for the capital, capital suburb, provincial cities, provincial towns and rural areas, respectively, are $5220,845,470,180$ and 55 people per $\mathrm{km}^{2} .^{17}$ Distances are small in Denmark - most people live within $25 \mathrm{~km}$ of a city with more than 30000 inhabitants and even closer to a psychiatric hospital.

\section{Study design and statistical analyses}

For each psychiatric disorder, individuals were followed up from the earliest age at which they may possibly develop the specific disorder or 1 January 1995, whichever came last, until onset of the outcome in question, death, emigration from Denmark or 31 December 2012, whichever came first. Note that since individuals were followed from 1995 onwards only, those with diagnoses prior to 1995 were excluded. The findings were therefore based entirely on incident cases diagnosed according to the more operational ICD-10 diagnostic classification system and during a period when both in-patient and out-patient information was used, except that the ICD-8 classification was used to censor people with a diagnosis prior to 1995 and to establish family history. Since many of the child psychiatric disorders were only registered in out-patient settings, the study cohort for the child psychiatric disorders included only individuals born in 1993 or later.

The incidence rate ratios (IRRs) associated with urbanicity at birth for each mental disorder outcome were estimated by $\log$ linear Poisson regression. All IRRs were adjusted for calendar period, age and gender, as well as the interaction between age and gender. Age and calendar period were treated as time-dependent variables, whereas all other variables were treated as variables independent of time. Potential confounders included maternal and paternal age at time of child's birth and history of mental illness in a parent or sibling. $P$-values and $95 \%$ confidence intervals were based on likelihood ratio tests. The adjusted-score test suggested that the regression models were not subject to overdispersion.

In addition to the categorical model (IRR for five levels of urbanisation) we used a continuous model that estimates trends to summarise the risk associated with urbanicity at birth. Specifically, the level of urbanisation was entered into the model as a trend variable with scores proportional to the logarithm of the relative population density ( 0 for rural areas, 0.26 for provincial towns, 0.47 for provincial cities, 0.60 for capital suburbs and 1 for the capital). Using this scoring, the estimated relative risk corresponds to the risk of birth in the capital compared with birth in the rural area using data from all degrees of urbanisation. As a result of the many tests performed, in this article we will denote estimates as statistically significant if the $P$-value is $<0.0025$, using a Bonferroni correction for multiple testing across the 20 psychiatric disorders we examined. This study was approved by the Danish Data Protection Agency.

\section{Results}

A total of 2894640 people born in Denmark 1955-2006 were followed from 1995 to 2012, using the ICD-10 classification.

Table 1 Number of new cases according to degree of urbanisation of place of birth in Denmark ${ }^{\text {a }}$

\begin{tabular}{|c|c|c|c|c|c|c|}
\hline Psychiatric disorder ${ }^{\mathrm{b}}$ & $\begin{array}{l}\text { ICD-10 } \\
\text { code }\end{array}$ & Capital & $\begin{array}{l}\text { Capital } \\
\text { suburb }\end{array}$ & $\begin{array}{l}\text { Provincial } \\
\text { city }\end{array}$ & $\begin{array}{l}\text { Provincial } \\
\text { town }\end{array}$ & $\begin{array}{l}\text { Rural } \\
\text { area }\end{array}$ \\
\hline Any psychiatric disorder & F00-F99 & 37728 & 28540 & 29316 & 77840 & 65090 \\
\hline Adult psychiatric disorder & F00-F69 & 19437 & 12263 & 14913 & 38256 & 28783 \\
\hline \multirow{3}{*}{$\begin{array}{l}\text { Mental and behavioural disorders due to psychoactive substance use } \\
\text { Mental and behavioural disorders due to alcohol use } \\
\text { Mental and behavioural disorders due to cannabis use }\end{array}$} & F10-F19 & 8752 & 4638 & 6113 & 14006 & 9737 \\
\hline & F10 & 6127 & 2725 & 4136 & 8837 & 6068 \\
\hline & F12 & 2565 & 1634 & 1561 & 3673 & 2501 \\
\hline \multirow{3}{*}{$\begin{array}{l}\text { Schizophrenia and related disorders } \\
\text { Schizophrenia } \\
\text { Schizoaffective disorder }\end{array}$} & F20-F29 & 4918 & 3090 & 2868 & 7822 & 5940 \\
\hline & $\mathrm{F} 20$ & 2826 & 1625 & 1668 & 4337 & 3246 \\
\hline & F25 & 444 & 194 & 309 & 744 & 505 \\
\hline \multirow{3}{*}{$\begin{array}{l}\text { Mood disorders } \\
\text { Bipolar disorder } \\
\text { Single and recurrent depressive disorder }\end{array}$} & F30-F39 & 12133 & 7962 & 9915 & 26278 & 19842 \\
\hline & F30-F31 & 1400 & 729 & 1360 & 2857 & 1999 \\
\hline & F32-F33 & 11067 & 7318 & 8918 & 24128 & 18237 \\
\hline Neurotic, stress-related and somatoform disorder & F40-F48 & 21509 & 15068 & 15208 & 39653 & 30655 \\
\hline \multirow{2}{*}{$\begin{array}{l}\text { Eating disorders } \\
\quad \text { Anorexia nervosa }\end{array}$} & F50 & 1980 & 1907 & 1858 & 4155 & 3772 \\
\hline & F50.0 & 587 & 566 & 523 & 1218 & 1199 \\
\hline Specific personality disorders & F60 & 7450 & 5337 & 5748 & 14601 & 10446 \\
\hline 'Mental retardation' & F70-F79 & 1282 & 1161 & 1269 & 3517 & 3557 \\
\hline \multirow{2}{*}{$\begin{array}{l}\text { Pervasive developmental disorders } \\
\text { Childhood autism }\end{array}$} & F84 & 1767 & 1695 & 1026 & 2705 & 3027 \\
\hline & F84.0 & 491 & 458 & 273 & 899 & 965 \\
\hline \multirow{2}{*}{$\begin{array}{l}\text { Behavioural and emotional disorders with onset in childhood } \\
\text { Hyperkinetic disorder }\end{array}$} & F90-F98 & 2608 & 3268 & 2460 & 6908 & 8346 \\
\hline & F90 & 1638 & 1991 & 1225 & 3986 & 4976 \\
\hline
\end{tabular}


Overall, the cohort was followed for 45325531 person-years, during which period 238514 members of the cohort had their first psychiatric contact with any psychiatric disorder. The list of psychiatric disorders examined with corresponding ICD-10 codes and the number of new cases during the follow-up period according to degree of urbanisation are presented in Table 1.

Table 2 shows IRRs under the categorical model for each of the psychiatric outcomes across the five categories of degrees of urbanisation of place of birth in Denmark, compared with people born in rural areas and summary estimates of the effect of birth in the capital compared with birth in rural areas (trend estimate). For all psychiatric disorders, except intellectual disability and behavioural and emotional disorders with onset in childhood, individuals born in the capital had a higher incidence rate than those born in rural areas. There was evidence of a doseresponse association between the degree of urbanisation and the IRR of the disorder in question.

Table 3 presents trend estimates for each psychiatric outcome adjusting for potential confounders. Adjusting for parental age did not substantially alter the trend estimates, whereas the inclusion of family history of mental illness in the model resulted in a reduction of trend estimates for most disorders. In the full model and in the majority of specific categories of mental disorders examined, the risk in individuals born in more urbanised areas is significantly increased. From this point onwards we refer to the fully adjusted estimates. For behavioural and emotional disorders with onset in childhood, including hyperkinetic disorder, the place of birth does not influence the risk of the disorder and for intellectual disability we found a significant reduction of the incidence in more urbanised areas (trend 0.86 , $P<0.0001)$.

Examination of the IRR of any psychiatric disorder for individuals born in the capital compared with individuals born in rural areas by age at diagnosis showed a high effect of urbanicity in young children, a decline to minimal effect around the ages of 5-10 (reflecting the lack of effect of urbanicity in behavioural and emotional disorders with onset in childhood), an increase during adolescence and a steady elevated IRR around 1.5 throughout adulthood.

\section{Discussion}

\section{Main findings}

In this study we found that birth in the capital or large cities was associated with elevated risk for developing mental illness in general. When the main categories of psychiatric diagnoses were examined separately, this association applied to most disorders with the exception of intellectual disability and emotional disorders with onset in childhood, including hyperkinetic disorder. For the remaining diagnostic categories the association was highly significant with the IRRs of birth in the capital $v$. birth in rural areas taking into account all levels of urbanicity (trend estimates) ranging from 2.17 to 1.15 .

\section{Comparison with previous findings}

The effect of urbanicity at birth on the incidence of any psychiatric disorder (trend 1.29, 95\% CI 1.27-1.30) was marginally higher than the estimate of a recent meta-analysis of total prevalence rates for psychiatric disorders (pooled adjusted odds ratio $(\mathrm{OR})=1.21) ;^{1}$ although the two methods are not directly comparable. When examining specific psychiatric outcomes, the stronger effect of urban birth was found for pervasive developmental disorders, schizophrenia and substance use disorders (trend $1.79,1.68$ and 1.57 , respectively). It has been suggested that the urban-rural differences in the risk of schizophrenia is not just an epiphenomenon of selective migration or differential service utilisation. ${ }^{6,7}$ For example, Pedersen \& Mortensen showed that the more years lived in a high degree of

\begin{tabular}{|c|c|c|c|c|c|c|c|}
\hline \multirow[b]{2}{*}{ Psychiatric disorder } & \multicolumn{5}{|c|}{ Categorical model, IRR (95\% Cl) } & \multicolumn{2}{|c|}{ Continuous model } \\
\hline & Capital & $\begin{array}{l}\text { Capital } \\
\text { suburb }\end{array}$ & $\begin{array}{l}\text { Provincial } \\
\text { city }\end{array}$ & $\begin{array}{l}\text { Provincial } \\
\text { town }\end{array}$ & $\begin{array}{l}\text { Rural } \\
\text { area }\end{array}$ & $\begin{array}{c}\text { Capital v. rural } \\
\text { area, IRR }(95 \% \mathrm{Cl})\end{array}$ & $P$ \\
\hline Any psychiatric disorder & $1.38(1.36-1.40)$ & $1.29(1.27-1.30)$ & $1.12(1.11-1.14)$ & $1.13(1.11-1.14)$ & 1.00 (ref) & $1.38(1.36-1.39)$ & $<0.0001$ \\
\hline Adult psychiatric disorder & $1.42(1.40-1.45)$ & $1.24(1.22-1.27)$ & $1.21(1.19-1.23)$ & $1.15(1.13-1.16)$ & 1.00 (ref) & $1.41(1.38-1.43)$ & $<0.0001$ \\
\hline $\begin{array}{l}\text { Mental and behavioural disorders due } \\
\text { to psychoactive substance use } \\
\text {... due to alcohol use } \\
\text {... due to cannabis use }\end{array}$ & $\begin{array}{l}1.79(1.74-1.84) \\
1.74(1.68-1.80) \\
2.50(2.36-2.64)\end{array}$ & $\begin{array}{l}1.42(1.37-1.47) \\
1.39(1.33-1.46) \\
1.85(1.74-1.97)\end{array}$ & $\begin{array}{l}1.45(1.40-1.50) \\
1.49(1.43-1.55) \\
1.53(1.43-1.63)\end{array}$ & $\begin{array}{l}1.22(1.19-1.25) \\
1.16(1.13-1.20) \\
1.34(1.27-1.41)\end{array}$ & $\begin{array}{l}1.00 \text { (ref) } \\
1.00 \text { (ref) } \\
1.00 \text { (ref) }\end{array}$ & $\begin{array}{l}1.76(1.71-1.81) \\
1.75(1.69-1.80) \\
2.47(2.34-2.60)\end{array}$ & $\begin{array}{l}<0.0001 \\
<0.0001 \\
<0.0001\end{array}$ \\
\hline $\begin{array}{l}\text { Schizophrenia and related disorders } \\
\text { Schizophrenia } \\
\text { Schizoaffective disorder }\end{array}$ & $\begin{array}{l}1.83(1.76-1.90) \\
1.86(1.77-1.96) \\
1.55(1.36-1.76)\end{array}$ & $\begin{array}{l}1.49(1.42-1.55) \\
1.42(1.34-1.50) \\
1.10(0.93-1.30) \\
\end{array}$ & $\begin{array}{l}1.14(1.09-1.19) \\
1.18(1.11-1.25) \\
1.29(1.11-1.48) \\
\end{array}$ & $\begin{array}{l}1.15(1.11-1.19) \\
1.13(1.08-1.18) \\
1.12(1.00-1.26)\end{array}$ & $\begin{array}{l}1.00 \text { (ref) } \\
1.00 \text { (ref) } \\
1.00 \text { (ref) }\end{array}$ & $\begin{array}{l}1.84(1.77-1.91) \\
1.87(1.78-1.96) \\
1.51(1.34-1.71) \\
\end{array}$ & $\begin{array}{l}<0.0001 \\
<0.0001 \\
<0.0001\end{array}$ \\
\hline $\begin{array}{l}\text { Mood disorders } \\
\text { Bipolar disorder } \\
\text { Single and recurrent depressive disorder }\end{array}$ & $\begin{array}{l}1.27(1.24-1.30) \\
1.31(1.22-1.40) \\
1.26(1.23-1.29)\end{array}$ & $\begin{array}{l}1.16(1.13-1.19) \\
1.07(0.98-1.17) \\
1.16(1.13-1.19) \\
\end{array}$ & $\begin{array}{l}1.16(1.13-1.18) \\
1.50(1.40-1.61) \\
1.13(1.10-1.16) \\
\end{array}$ & $\begin{array}{l}1.13(1.11-1.15) \\
1.15(1.09-1.22) \\
1.13(1.11-1.15)\end{array}$ & $\begin{array}{l}1.00 \text { (ref) } \\
1.00 \text { (ref) } \\
1.00 \text { (ref) }\end{array}$ & $\begin{array}{l}1.25(1.22-1.27) \\
1.29(1.21-1.37) \\
1.24(1.21-1.27)\end{array}$ & $\begin{array}{l}<0.0001 \\
<0.0001 \\
<0.0001\end{array}$ \\
\hline $\begin{array}{l}\text { Neurotic, stress-related and somatoform } \\
\text { disorders }\end{array}$ & $1.55(1.53-1.58)$ & $1.43(1.40-1.45)$ & $1.18(1.16-1.20)$ & $1.15(1.13-1.16)$ & 1.00 (ref) & $1.57(1.54-1.59)$ & $<0.0001$ \\
\hline $\begin{array}{l}\text { Eating disorders } \\
\quad \text { Anorexia nervosa }\end{array}$ & $\begin{array}{l}1.52(1.44-1.60) \\
1.54(1.39-1.70)\end{array}$ & $\begin{array}{l}1.42(1.35-1.50) \\
1.35(1.22-1.49)\end{array}$ & $\begin{array}{l}1.31(1.24-1.39) \\
1.23(1.11-1.37)\end{array}$ & $\begin{array}{l}1.12(1.07-1.17) \\
1.13(1.04-1.22)\end{array}$ & $\begin{array}{l}1.00 \text { (ref) } \\
1.00 \text { (ref) }\end{array}$ & $\begin{array}{l}1.57(1.50-1.66) \\
1.56(1.42-1.71)\end{array}$ & $\begin{array}{l}<0.0001 \\
<0.0001\end{array}$ \\
\hline Specific personality disorder & $1.55(1.50-1.59)$ & $1.44(1.40-1.49)$ & $1.26(1.22-1.30)$ & $1.18(1.15-1.21)$ & 1.00 (ref) & $1.55(1.51-1.60)$ & $<0.0001$ \\
\hline 'Mental retardation' & $0.92(0.87-0.99)$ & $0.95(0.89-1.02)$ & $0.95(0.90-1.02)$ & $1.04(1.00-1.09)$ & 1.00 (ref) & $0.91(0.86-0.96)$ & 0.0016 \\
\hline $\begin{array}{l}\text { Pervasive developmental disorders } \\
\text { Childhood autism }\end{array}$ & $\begin{array}{l}1.76(1.66-1.87) \\
1.49(1.34-1.66)\end{array}$ & $\begin{array}{l}1.64(1.54-1.74) \\
1.39(1.24-1.55) \\
\end{array}$ & $\begin{array}{l}1.02(0.95-1.10) \\
0.85(0.74-0.97)\end{array}$ & $\begin{array}{l}1.15(1.09-1.21) \\
1.20(1.10-1.32)\end{array}$ & $\begin{array}{l}1.00 \text { (ref) } \\
1.00 \text { (ref) }\end{array}$ & $\begin{array}{l}1.81(1.71-1.91) \\
1.45(1.31-1.61)\end{array}$ & $\begin{array}{l}<0.0001 \\
<0.0001\end{array}$ \\
\hline $\begin{array}{l}\text { Behavioural and emotional disorders } \\
\text { with onset in childhood } \\
\text { Hyperkinetic disorder }\end{array}$ & $\begin{array}{l}0.95(0.90-0.99) \\
0.99(0.93-1.04)\end{array}$ & $\begin{array}{l}1.14(1.10-1.19) \\
1.17(1.11-1.23)\end{array}$ & $\begin{array}{l}0.89(0.85-0.93) \\
0.74(0.69-0.79)\end{array}$ & $\begin{array}{l}1.07(1.03-1.10) \\
1.03(0.99-1.08)\end{array}$ & $\begin{array}{l}1.00 \text { (ref) } \\
1.00 \text { (ref) }\end{array}$ & $\begin{array}{l}0.98(0.94-1.01) \\
0.99(0.94-1.05)\end{array}$ & $\begin{array}{l}0.2149 \\
0.8128\end{array}$ \\
\hline
\end{tabular}




\begin{tabular}{|c|c|c|c|c|c|c|c|c|}
\hline \multirow[b]{2}{*}{ Psychiatric disorder } & \multicolumn{2}{|c|}{ Basic adjustment $^{\mathrm{a}}$} & \multicolumn{2}{|c|}{ Second adjustment ${ }^{\mathrm{b}}$} & \multicolumn{2}{|c|}{ Third adjustment $^{\mathrm{c}}$} & \multicolumn{2}{|c|}{ Fourth adjustment $^{d}$} \\
\hline & IRR $(95 \% \mathrm{Cl})$ & $P^{\mathrm{e}}$ & IRR (95\% Cl) & $P^{\mathrm{e}}$ & IRR $(95 \% \mathrm{Cl})$ & $p^{e}$ & IRR (95\% Cl) & $p^{e}$ \\
\hline Any psychiatric disorder & $1.38(1.36-1.39)$ & $<0.0001$ & $1.37(1.35-1.39)$ & $<0.0001$ & $1.29(1.28-1.31)$ & $<0.0001$ & $1.29(1.27-1.30)$ & $<0.0001$ \\
\hline Adult psychiatric disorder & $1.41(1.38-1.43)$ & $<0.0001$ & $1.40(1.37-1.42)$ & $<0.0001$ & $1.31(1.28-1.33)$ & $<0.0001$ & $1.30(1.28-1.32)$ & $<0.0001$ \\
\hline $\begin{array}{l}\text { Mental and behavioural disorders due } \\
\text { to psychoactive substance use } \\
\ldots \text {. due to alcohol use } \\
\text {.. due to cannabis use }\end{array}$ & $\begin{array}{l}1.76(1.71-1.81) \\
1.75(1.69-1.80) \\
2.47(2.34-2.60)\end{array}$ & $\begin{array}{l}<0.0001 \\
<0.0001 \\
<0.0001\end{array}$ & $\begin{array}{l}1.73(1.68-1.78) \\
1.72(1.66-1.78) \\
2.43(2.31-2.56)\end{array}$ & $\begin{array}{l}<0.0001 \\
<0.0001 \\
<0.0001\end{array}$ & $\begin{array}{l}1.60(1.56-1.65) \\
1.60(1.55-1.65) \\
2.19(2.08-2.30)\end{array}$ & $\begin{array}{l}<0.0001 \\
<0.0001 \\
<0.0001\end{array}$ & $\begin{array}{l}1.57(1.53-1.62) \\
1.58(1.52-1.63) \\
2.17(2.06-2.28)\end{array}$ & $\begin{array}{l}<0.0001 \\
<0.0001 \\
<0.0001\end{array}$ \\
\hline $\begin{array}{l}\text { Schizophrenia and related disorders } \\
\text { Schizophrenia } \\
\text { Schizoaffective disorder }\end{array}$ & $\begin{array}{l}1.84(1.77-1.91) \\
1.87(1.78-1.96) \\
1.51(1.34-1.71)\end{array}$ & $\begin{array}{l}<0.0001 \\
<0.0001 \\
<0.0001\end{array}$ & $\begin{array}{l}1.84(1.77-1.91) \\
1.87(1.78-1.97) \\
1.54(1.36-1.74)\end{array}$ & $\begin{array}{l}<0.0001 \\
<0.0001 \\
<0.0001\end{array}$ & $\begin{array}{l}1.67(1.61-1.74) \\
1.69(1.61-1.77) \\
1.34(1.18-1.51)\end{array}$ & $\begin{array}{l}<0.0001 \\
<0.0001 \\
<0.0001\end{array}$ & $\begin{array}{l}1.68(1.62-1.74) \\
1.69(1.61-1.78) \\
1.36(1.20-1.54)\end{array}$ & $\begin{array}{l}<0.0001 \\
<0.0001 \\
<0.0001\end{array}$ \\
\hline $\begin{array}{l}\text { Mood disorders } \\
\text { Bipolar disorder } \\
\text { Single and recurrent depressive } \\
\text { disorder }\end{array}$ & $\begin{array}{l}1.25(1.22-1.27) \\
1.29(1.21-1.37) \\
1.24(1.21-1.27)\end{array}$ & $\begin{array}{l}<0.0001 \\
<0.0001 \\
<0.0001\end{array}$ & $\begin{array}{l}1.24(1.22-1.27) \\
1.29(1.21-1.37) \\
1.23(1.20-1.26)\end{array}$ & $\begin{array}{l}<0.0001 \\
<0.0001 \\
<0.0001\end{array}$ & $\begin{array}{l}1.16(1.14-1.19) \\
1.17(1.10-1.25)\end{array}$ & $\begin{array}{l}<0.0001 \\
<0.0001 \\
<0.0001\end{array}$ & $\begin{array}{l}1.16(1.14-1.19) \\
1.17(1.10-1.25)\end{array}$ & $\begin{array}{l}<0.0001 \\
<0.0001 \\
<0.0001\end{array}$ \\
\hline $\begin{array}{l}\text { Neurotic, stress-related and } \\
\text { somatoform disorders }\end{array}$ & $1.57(1.54-1.59)$ & $<0.0001$ & $1.56(1.53-1.58)$ & $<0.0001$ & $1.46(1.43-1.48)$ & $<0.0001$ & $1.45(1.43-1.47)$ & $<0.0001$ \\
\hline $\begin{array}{l}\text { Eating disorders } \\
\text { Anorexia nervosa }\end{array}$ & $\begin{array}{l}1.57(1.50-1.66) \\
1.56(1.42-1.71)\end{array}$ & $\begin{array}{l}<0.0001 \\
<0.0001\end{array}$ & $\begin{array}{l}1.57(1.49-1.65) \\
1.56(1.42-1.71)\end{array}$ & $\begin{array}{l}<0.0001 \\
<0.0001\end{array}$ & $\begin{array}{l}1.53(1.45-1.61) \\
1.54(1.40-1.69)\end{array}$ & $\begin{array}{l}<0.0001 \\
<0.0001\end{array}$ & $\begin{array}{l}1.53(1.45-1.61) \\
1.53(1.40-1.68)\end{array}$ & $\begin{array}{l}<0.0001 \\
<0.0001\end{array}$ \\
\hline Specific personality disorder & $1.55(1.51-1.60)$ & $<0.0001$ & $1.54(1.50-1.58)$ & $<0.0001$ & $1.42(1.38-1.46)$ & $<0.0001$ & $1.41(1.37-1.44)$ & $<0.0001$ \\
\hline 'Mental retardation' & $0.91(0.86-0.96)$ & 0.0016 & $0.92(0.87-0.98)$ & 0.0051 & $0.85(0.80-0.90)$ & $<0.0001$ & $0.86(0.81-0.91)$ & $<0.0001$ \\
\hline $\begin{array}{l}\text { Pervasive developmental disorders } \\
\text { Childhood autism }\end{array}$ & $\begin{array}{l}1.81(1.71-1.91) \\
1.45(1.31-1.61)\end{array}$ & $\begin{array}{l}<0.0001 \\
<0.0001\end{array}$ & $\begin{array}{l}1.84(1.74-1.94) \\
1.47(1.32-1.62)\end{array}$ & $\begin{array}{l}<0.0001 \\
<0.0001\end{array}$ & $\begin{array}{l}1.76(1.67-1.86) \\
1.41(1.27-1.56)\end{array}$ & $\begin{array}{l}<0.0001 \\
<0.0001\end{array}$ & $\begin{array}{l}1.79(1.69-1.89) \\
1.42(1.28-1.58)\end{array}$ & $\begin{array}{l}<0.0001 \\
<0.0001\end{array}$ \\
\hline $\begin{array}{l}\text { Behavioural and emotional disorders } \\
\text { with onset in childhood } \\
\text { Hyperkinetic disorder }\end{array}$ & $\begin{array}{l}0.98(0.94-1.01) \\
0.99(0.94-1.05)\end{array}$ & $\begin{array}{l}0.2149 \\
0.8128\end{array}$ & $\begin{array}{l}1.04(1.00-1.08) \\
1.07(1.01-1.12)\end{array}$ & $\begin{array}{l}0.0526 \\
0.0142\end{array}$ & $\begin{array}{l}0.93(0.89-0.97) \\
0.96(0.91-1.01)\end{array}$ & $\begin{array}{l}0.0003 \\
0.0884\end{array}$ & $\begin{array}{l}0.99(0.95-1.03) \\
1.02(0.97-1.08)\end{array}$ & $\begin{array}{l}0.4880 \\
0.4119\end{array}$ \\
\hline
\end{tabular}

urbanisation the higher the risk of schizophrenia and, for fixed urbanicity at 15th birthday, the IRR increased with increasing degree of urbanisation at place of birth. ${ }^{18}$

Contrary to prevalence studies of urban-rural differences in alcohol consumption or misuse, ${ }^{19}$ we found that urban birth increases significantly the risk of developing alcohol-related disorders (trend 1.58) and we noticed an even stronger effect for cannabis use (trend 2.17). The latter could be partially explained by the easier access, greater peer pressure and more tolerant attitude towards substance use in people growing up in cities. ${ }^{20}$

The strong association with pervasive developmental disorders is consistent with a recent meta-analysis of the prevalence of autism spectrum disorders that showed an over twofold increase in typical autism and autism spectrum disorders in studies conducted in urban environments in comparison with studies in rural/mixed environments. ${ }^{21}$ The variation in prevalence rates of pervasive developmental disorders between studies is remarkable ${ }^{22}$ and the recent increase in the incidence of these disorders may reflect a broadening of the concept of pervasive developmental disorders or improved detection and recognition of the disorder. ${ }^{23}$ Hence, urban-rural differences in autism may partially reflect differences in service availability, recognition rates and awareness of autism spectrum disorders among both the lay public and professionals.

The effect of urban birth on the incidence of neurotic and stress-related disorders, eating disorders and personality disorders were similar (trend 1.41-1.53). These findings contrast with a recent systematic review of the global prevalence of anxiety disorders that found a higher rate of anxiety in rural populations. ${ }^{24}$ However, this review presents comparisons of urban/rural prevalence rates estimated from different studies; hence, these previous results should be interpreted with caution.
Unlike most prevalence studies, which find a stronger effect for mood disorders in comparison with anxiety disorders, ${ }^{1,25}$ our estimate of the effect of urbanicity on the incidence of mood disorders was much lower (trend 1.16), but still significant. Similar effect sizes were estimated for depression and bipolar disorder (trend 1.15 and 1.17, respectively), underlining the similarity of bipolar with other mood disorders. A recent population-based cohort study found that the incidence of bipolar disorder was not different in urban compared with non-urban areas. However, this study was probably underpowered and the crude IRR estimated from the data presented (1.14) was very similar to our findings. ${ }^{9}$ This is much lower than the effect of urbanicity on schizophrenia - possibly a point of difference between bipolar disorder and schizophrenia. The effect of urbanicity on schizoaffective disorder (trend 1.36) lies between the two conditions.

One interesting finding was that urban birth appears to be slightly protective for intellectual disability. This is similar to studies that found higher prevalence of intellectual disability in rural areas. ${ }^{26,27}$ Reasons suggested include inbreeding and selective migration, with more competent people moving to the cities. Evidence from recent studies indicates that increased administrative prevalence of autism (as measured using educational and other administrative data) is accompanied by concurrent decline in the prevalence of intellectual disability and other developmental disabilities. ${ }^{28}$ One possibility that could account for some of the converse effect of urban environment on intellectual disability (reduced incidence) and pervasive developmental disorders (increased incidence) could be differential diagnostic substitution ${ }^{29}$ between urban and rural areas.

The only other diagnostic category that did not show increased incidence in urban environments was behavioural and 
emotional disorders with onset in childhood and hyperkinetic disorder specifically, unlike a recent study from Germany that found that the prevalence of ADHD increased with a higher degree of urbanisation ${ }^{3}$ and a recent population-based study from Taiwan that identified increased incidence of all neurodevelopmental disorders (intellectual disability, autism and ADHD) in urban environments. ${ }^{12}$ Despite some evidence of aetiological and clinical overlap between autism and ADHD, ${ }^{30}$ our study suggests that risk factors associated with urbanicity differentiate the two disorders.

The results of this study, with urbanicity acting as a common risk factor for most mental disorders, can be interpreted in the context of a continuum model for mental illness, not restricted by current diagnostic boundaries, with psychiatric syndromes having quantitative differences apart from qualitative differences in causal mechanisms. ${ }^{10}$ This adds to previous evidence that the risk of schizophrenia is associated with a family history of a wide range of mental disorders, not confined to psychosis. ${ }^{31}$ Alongside recent molecular evidence of shared genetic aetiology for psychiatric disorders, ${ }^{32}$ our findings provide insights into the shared causation of psychiatric disorders from an epidemiological perspective. Therefore, we argue that discussions about the validity of the Kraepelinian dichotomy and continuum models that include only psychotic disorders are an oversimplification of the full picture of mental illness.

Epidemiological studies measuring differences in incidence are not equipped to examine specific aetiopathogenic mechanisms. Urbanicity is a 'proxy' for underlying risk factors and a number of potential causes have been proposed in the schizophrenia literature. These include individual or area characteristics such as differences in diet, exposure to infections, pollutants or toxins, household crowding, obstetric complications, ethnic density, deprivation and social fragmentation or reduced social cohesion. ${ }^{33}$ Evidence from a Danish sibling design suggests that whatever the causes responsible for these urban-rural differences in schizophrenia risk they are mainly operating at a family rather than an individual level. ${ }^{34}$ However, we cannot extrapolate these theories to the totality of mental illness and the new evidence that urbanicity acts as a risk factor for most mental disorders indicates the need to reconsider or broaden the search for causal factors.

It has been suggested that control over the internal housing environment, quality of housing, presence of valued 'escape facilities' (such as parks, public spaces, leisure and recreation), crime and fear of crime, and social participation underlie the interface between the urban and physical environment and mental well-being. ${ }^{35}$ Type of dwelling, noise, pollution, crowding and density, accessibility, exposure and access to nature have also been associated with psychological symptoms ${ }^{36}$ and previous evidence exists that improvement in the social environment is associated with improved mental health of the population. ${ }^{37}$ All these factors and other differences between rural and urban birth and upbringing need to be considered as potential causes for the differences in the incidence of mental disorders.

\section{Strengths and limitations}

This is the first study that investigates the effect of urban birth on the incidence of the full spectrum of psychiatric disorders. Strengths of the study include the large sample size that includes the entire population of Denmark, with complete ascertainment of the patients treated in psychiatric departments during the follow-up period, and exposure to the risk factor before the illness onset, which eliminates the possibility of selective migration. In addition, the adjustment for potential confounders such as parental age and family history reduces the possibility that the observed differences in the incidence of mental disorders reflect only differential exposure to other known risk factors. Since we only include people born in Denmark with both parents also born in Denmark, our findings are not influenced by foreign immigration patterns.

A limitation of the study is that individuals with mental illness were identified through the psychiatric case register, as opposed to clinical examination with structured interviews. Although the use of register-based diagnoses has several strengths, they may lack the reliability that can be obtained by well-trained interviewers using operationalised diagnostic interviews. ${ }^{38}$ Although systematic studies validating all clinical diagnoses presented in this study do not exist, validation of some diagnoses (schizophrenia, single depressive episode, affective disorder, dementia, autism) has been carried out with good results. ${ }^{39,40}$ Furthermore, the use of the psychiatric case register for the identification of family history may provide more reliable confounder adjustment than using family history information collected retrospectively usually by examining patients and controls, a potential source for selection and recall bias.

Another limitation is that the individuals with mental illness included in our analyses were identified through in- or outpatient treatment in psychiatric settings. Psychological problems are among the most common reasons for presentation in primary care in Denmark (9.3\% of all encounters), with only a small proportion (less than $5 \%$ across all diagnoses) being referred to out-patient clinics or for hospital admission. ${ }^{41}$ We therefore cannot draw conclusions about the effect of urbanicity at birth on less severe disorders that do not require specialist treatment. Since urbanicity is a 'proxy' for unknown risk factors, epidemiological studies in developed, highly urbanised countries, like Denmark alone, may not be sufficient to reveal the mechanisms underlying the urban effect and the findings cannot be generalised in low- and middle-income countries. However, two recent studies from low-income countries ${ }^{42,43}$ offer evidence that the association of urbanicity with mental illness is not limited to high-income countries.

Although examination of urbanicity at birth and adjustment for family history eliminates the possibility of selective migration to urban centres of individuals or families after the development of mental illness, there is still a possibility of selective migration towards urban areas of families with traits or subtle symptoms below the threshold for treatment by psychiatric services. In addition, we cannot exclude the possibility of urban-rural differences in service utilisation, as a proportion of people do not change environment during their lives; hence, the place of residence at diagnosis is correlated with the place of birth.

\section{Implications}

In conclusion, we found a dose-response association between the degree of urbanisation at birth and the incidence of the full spectrum of mental disorders. We confirmed previous associations of urbanicity with risk for schizophrenia, bipolar disorder and autism and expanded the findings to substance use, mood, neurotic, eating and personality disorders. Potential explanations include urban-rural differences in service utilisation, diet, stress, lifestyle, family-level factors, infections, complications during pregnancy, quality of housing, fear of crime and social participation. The only disorder where birth in an urban environment appeared to be protective was intellectual disability. Our findings that urban birth increases the risk for most mental disorders, combined with current evidence on their global burden to individuals and society ${ }^{44}$ urge the research community to develop testable hypotheses of risk factors underpinning the effect of urbanicity on mental health. Replication of the findings in a different population is crucial before definite conclusions can be 
drawn. Furthermore, identification of specific factors that underlie the association between early life exposure to urban environment and mental illness would be relevant for public policies, including public health and town planning policies.

Evangelos Vassos, MD, PhD, Social, Genetic and Developmental Psychiatry Centre Institute of Psychiatry, King's College London, London, UK; Esben Agerbo, DrMedSC, National Centre for Register-Based Research, Aarhus University, Business and Socia Sciences, Aarhus, Centre for Integrated Register-based Research, CIRRAU, Aarhus University, Aarhus and The Lundbeck Foundation Initiative for Integrative Psychiatric Research, iPSYCH, Denmark; Ole Mors, MD, PhD, The Lundbeck Foundation Initiative for Integrative Psychiatric Research, iPSYCH, and Research Department P, Aarhus University Hospital, Risskov, Denmark; Carsten Bøcker Pedersen, DrMedSc, National Centre for Register-Based Research, Aarhus University, Business and Socia Sciences, Aarhus, Centre for Integrated Register-based Research, CIRRAU, Aarhus University, Aarhus and The Lundbeck Foundation Initiative for Integrative Psychiatric Research, iPSYCH, Denmark

Correspondence: Evangelos Vassos, Box P082, MRC SGDP Centre Institute of Psychiatry, De Crespigny Park, London SE5 8AF, UK. Email: evangelos.vassos@kcl.ac.uk

First received 24 Nov 2014, final revision 10 Apr 2015, accepted 6 May 2015

\section{Funding}

This study was funded by the Stanley Medical Research Institute, Bethesda, Maryland and by grants from The Lundbeck Foundation, Denmark. E.V. was supported by a Guy's and St Thomas Charity Grant and the NIHR Biomedical Research Centre at the South London St Thomas Charity Grant and the NIHR Biomedical Research Centre at the South London involvement in any aspect of the study.

\section{References}

1 Peen J, Schoevers RA, Beekman AT, Dekker J. The current status of urbanrural differences in psychiatric disorders. Acta Psychiatr Scand 2010; 121: 84-93.

2 van Son GE, van Hoeken D, Bartelds Al, van Furth EF, Hoek HW. Urbanisation and the incidence of eating disorders. Br J Psychiatry 2006; 189: 562-3.

3 Knopf $\mathrm{H}$, Holling $\mathrm{H}$, Huss $\mathrm{M}$, Schlack R. Prevalence, determinants and spectrum of attention-deficit hyperactivity disorder (ADHD) medication of children and adolescents in Germany: results of the German Health Interview and Examination Survey (KiGGS). BMJ Open 2012; 2: e000477.

4 Freeman H. Schizophrenia and city residence. Br J Psychiatry 1994; 164 (suppl 23): 39-50.

5 Mortensen PB, Pedersen CB, Westergaard T, Wohlfahrt J, Ewald H, Mors O et al. Effects of family history and place and season of birth on the risk of schizophrenia. N Engl J Med 1999; 340: 603-8.

6 Vassos E, Pedersen CB, Murray RM, Collier DA, Lewis CM. Meta-analysis of the association of urbanicity with schizophrenia. Schizophr Bull 2012; 38: $1118-23$.

7 van Os J, Kenis G, Rutten BP. The environment and schizophrenia. Nature 2010; 468: 203-12.

8 Pedersen $\mathrm{CB}$, Mortensen PB. Urbanicity during upbringing and bipolar affective disorders in Denmark. Bipolar Disord 2006; 8: 242-7.

9 Kroon JS, Wohlfarth TD, Dieleman J, Sutterland AL, Storosum JG, Denys D, et al. Incidence rates and risk factors of bipolar disorder in the general population: a population-based cohort study. Bipolar Disord 2013; 15: 306-13.

10 Laursen TM, Munk-Olsen T, Nordentoft M, Bo Mortensen P. A comparison of selected risk factors for unipolar depressive disorder, bipolar affective disorder, schizoaffective disorder, and schizophrenia from a Danish population-based cohort. J Clin Psychiatry 2007; 68: 1673-81.

11 Sundquist K, Frank G, Sundquist J. Urbanisation and incidence of psychosis and depression: follow-up study of 4.4 million women and men in Sweden. Br J Psychiatry 2004; 184: 293-8.

12 Chen $\mathrm{CY}$, Liu CY, Su WC, Huang SL, Lin KM. Factors associated with the diagnosis of neurodevelopmental disorders: a population-based longitudina study. Pediatrics 2007; 119: e435-43.

13 Lauritsen MB, Astrup A, Pedersen CB, Obel C, Schendel DE, Schieve L, et al. Urbanicity and autism spectrum disorders. J Autism Dev Disord 2014; 44 394-404.

14 Mors O, Perto GP, Mortensen PB. The Danish Psychiatric Central Research Register. Scand J Public Health 2011; 39 (suppl 7): 54-7.

15 World Health Organization. International Statistical Classification of Diseases and Related Health Problems (ICD-8). WHO, 1967.

16 World Health Organization. The ICD-10 Classification of Mental and Behavioura Disorders: Clinical Descriptions and Diagnostic Guidelines. WHO, 1992.

17 Statistics Denmark. Befolkningen i Kommunerne 1. Januar 1997. [Population in municipalities 1 January 1997.] Statistics Denmark, 1997.
18 Pedersen $C B$, Mortensen PB. Evidence of a dose-response relationship between urbanicity during upbringing and schizophrenia risk. Arch Gen Psychiatry 2001; 58: 1039-46.

19 Donath C, Grassel E, Baier D, Pfeiffer C, Karagülle D, Bleich S, et al. Alcohol consumption and binge drinking in adolescents: comparison of different migration backgrounds and rural vs. urban residence: a representative study. BMC Public Health 2011; 11: 84.

20 Flash Eurobarometer. Young People and Drugs. European Commission, 2004

21 Williams JG, Higgins JP, Brayne CE. Systematic review of prevalence studies of autism spectrum disorders. Arch Dis Child 2006; 91: 8-15.

22 Fombonne E. The prevalence of autism. JAMA 2003; 289: 87-9

23 Chakrabarti S, Fombonne E. Pervasive developmental disorders in preschool children. JAMA 2001; 285: 3093-9.

24 Baxter AJ, Scott KM, Vos T, Whiteford HA. Global prevalence of anxiety disorders: a systematic review and meta-regression. Psychol Med 2013; 43 897-910.

25 Romans S, Cohen M, Forte $\mathrm{T}$. Rates of depression and anxiety in urban and rural Canada. Soc Psychiatry Psychiatr Epidemiol 2011; 46: 567-75.

26 Lai DC, Tseng YC, Hou YM, Guo HR. Gender and geographic differences in the prevalence of intellectual disability in children: analysis of data from the national disability registry of Taiwan. Res Dev Disabil 2012; 33: 2301-7.

27 Sondenaa E, Rasmussen K, Nottestad JA, Lauvrud C. Prevalence of intellectual disabilities in Norway: domestic variance. J Intellect Disabil Res 2010; 54: 161-7.

$28 \mathrm{Coo} \mathrm{H}$, Ouellette-Kuntz H, Lloyd JE, Kasmara L, Holden JJ, Lewis ME. Trends in autism prevalence: diagnostic substitution revisited. J Autism Dev Disord 2008; 38: 1036-46.

29 King $M$, Bearman P. Diagnostic change and the increased prevalence of autism. Int J Epidemiol 2009; 38: 1224-34.

30 Taurines R, Schwenck C, Westerwald E, Sachse M, Siniatchkin M, Freitag C. ADHD and autism: differential diagnosis or overlapping traits? A selective review. Atten Defic Hyperact Disord 2012; 4: 115-39.

31 Mortensen PB, Pedersen MG, Pedersen CB. Psychiatric family history and schizophrenia risk in Denmark: which mental disorders are relevant? Psychol Med 2010; 40: 201-10.

32 Cross-Disorder Group of the Psychiatric Genomics C, Lee SH, Ripke S, Neale BM, Faraone SV, Purcell SM, et al. Genetic relationship between five psychiatric disorders estimated from genome-wide SNPS. Nat Genet 2013; 45: $984-94$

33 Allardyce J, Boydell J. Review: the wider social environment and schizophrenia. Schizophr Bull 2006; 32: 592-8.

34 Pedersen $\mathrm{CB}$, Mortensen PB. Are the cause(s) responsible for urban-rural differences in schizophrenia risk rooted in families or in individuals? $\mathrm{Am} \mathrm{J}$ Epidemiol 2006; 163: 971-8.

35 Chu A, Thorne A, Guite H. The impact on mental well-being of the urban and physical environment: an assessment of the evidence. J Public Ment Health 2004; 3: 17-32.

36 Cooper R, Boyko C, Codinhoto R. State-of-Science Review: SR-DR2. The Effect of the Physical Environment on Mental Wellbeing. Mental Capital and Wellbeing: Making the Most of Ourselves in the 21st Century. The Government Office for Science, 2008

37 Dalgard OS, Tambs K. Urban environment and mental health. A longitudinal study. Br J Psychiatry 1997; 171: 530-6.

38 Eaton WW, Hall AL, Macdonald R, McKibben J. Case identification in psychiatric epidemiology: a review. Int Rev Psychiatry 2007; 19: 497-507.

39 Lauritsen MB, Jorgensen M, Madsen KM, Lemcke S, Toft S, Grove J, et al. Validity of childhood autism in the Danish Psychiatric Central Register: findings from a cohort sample born 1990-1999. J Autism Dev Disord 2010; 40: $139-48$.

40 Uggerby $\mathrm{P}$, Ostergaard SD, Roge R, Correll CU, Nielsen J. The validity of the schizophrenia diagnosis in the Danish Psychiatric Central Research Register is good. Dan Med J 2013; 60: A4578.

41 Moth G, Olesen F, vedsted P. Reasons for encounter and disease patterns in Danish primary care: changes over 16 years. Scand J Prim Health Care 2012; 30: $70-5$.

42 Lundberg $\mathrm{P}$, Cantor-Graae E, Rukundo G, Ashaba S, Ostergren PO. Urbanicity of place of birth and symptoms of psychosis, depression and anxiety in Uganda. Br J Psychiatry 2009; 195: 156-62.

43 Prina AM, Ferri CP, Guerra M, Brayne C, Prince M. Prevalence of anxiety and its correlates among older adults in Latin America, India and China: crosscultural study. Br J Psychiatry 2011; 199: 485-91.

44 Murray CJ, Vos T, Lozano R, et al. Disability-adjusted life years (DALYS) for 291 diseases and injuries in 21 regions, 1990-2010: a systematic analysis for the Global Burden of Disease Study 2010. Lancet 2012; 380: 2197-223. 